DOI: 10.17148/IARJSET.2022.9142

\title{
Determination of XRD in Advanced Nanomaterials
}

\author{
Dr. P Vijaya Lakshmi ${ }^{1}$, Dr. Alla Srivani ${ }^{2}$, O Sreedevi ${ }^{3}$ \\ ${ }^{1}$ Assistant Professor, Department of BS\&H, Seshsadri Rao Gudlavalleru Engineering college, \\ Gudlavalleru, Andhra Pradesh \\ ${ }^{2}$ Associate Professor, Department of Science, Vasireddy Venkatadri Institute of Technology, Guntur, Andhra Pradesh \\ ${ }^{3}$ Assistant Professor,Department of BS\&H, Women's Engineering college, \\ Bapatla, Andhra Pradesh
}

\begin{abstract}
X-beam diffraction (XRD) is an amazing asset generally utilized in examination and industry. While XRD is generally notable for subjective and quantitative investigations of glasslike progressively eases in materials, undeniably more data can be gotten from a cautious examination of the diffraction designs or by utilizing explicit XRD settings: i.e., portrayal of strong arrangements, crystallite size and shape, gem direction, inside flexible strains/stresses at variou s levels, impact of temperature, close surface portrayal and so forth The targets of this paper are first to sum up a few fundamental standards of X-beam diffraction, and close to give a few instances of uses of XRD in the field of earthenware production materials.
\end{abstract}

Keywords: XRD Analysis, Advanced Materials, Peak Position and X-Ray wavelength.

\section{INTRODUCTION:}

XRD is a method utilized to decide the hidden precious stone construction of a material; it empowers confirmation of the crystallinity and design of an example yet gives no data of a synthetic sort. Fitting XRD examples can permit computation of the material cross section boundaries, the direction of a precious stone (or grain), stress in glasslike areas, and optional stages in the example. It is for the most part a mass portrayal strategy and produces a normal diffraction design for the area estimated. XRD is a non destructive strategy which can be directed at room temperature and strain.

X-beam diffraction (XRD) is an essential method for portrayal of mixtures in light of diffraction design. Glasslike materials have long-range requesting, which is seen as sharp tops in XRD and obvious utilizing Bragg's condition. Braag's condition relates the frequency of X-beam, interplanar separating in the precious stone, and looking point of rate. El-Latif et al. [38] incorporated nano-zirconium vanadate inorganic IEX pitch for sorption of cesium, cobalt, and nickel from a watery arrangement. Zirconium vanadate particle exchangers were incorporated utilizing three unmistakable strategies: homogeneous precipitation, sol-gel precipitation, and aqueous.

Likewise, tests were given soluble treatment while combining utilizing sol-gel precipitation and aqueous strategies. It very well may be seen that nano composite orchestrated utilizing sol-gel method addresses formless nature of the pitch alongside minor glasslike tops. Sol-gel strategy alongside antacid therapy portrays a comparative XRD design, with sharp pinnacles of higher force, demonstrating an expansion in crystallinity inferable from soluble base treatment.

The XRD design for nano composite integrated utilizing homogeneous precipitation strategy shows the presence of a few sharp tops (around 32 levels) of higher power in contrast with the pitches blended utilizing sol-gel method. Accordingly the gum combined utilizing homogeneous precipitation technique can be named as polycrystalline material. On account of aqueous strategy, the blended nano composite has a more serious level of crystallinity in contrast with the other two techniques, with extra tops at 47 and 63 degrees, individually, saw in the XRD design. As seen on account of sol-gel procedure, on account of aqueous technique for combination, crystallinity expanded with the therapy of soluble base, which is affirmed by expanded force of the tops in XRD design. 
International Advanced Research Journal in Science, Engineering and Technology

Impact Factor 7.105 Vol. 9, Issue 1, January 2022

DOI: 10.17148/IARJSET.2022.9142

Table-1:

\begin{tabular}{|l|l|l|l|l|}
\hline S1.No & $\begin{array}{l}\text { Peak } \\
\text { position } \\
2 \theta\end{array}$ & $\begin{array}{l}\text { X-ray } \\
\text { Wavelength }\end{array}$ & $\begin{array}{l}\text { Reflection } \\
\text { order }\end{array}$ & $\begin{array}{l}\text { XRD d Value } \\
\mathrm{nm}\end{array}$ \\
\hline 1 & 10 & 0.001 & 1 & 0.01 \\
2 & 20 & 0.015 & 2 & 0.09 \\
3 & 30 & 0.017 & 3 & 0.10 \\
4 & 40 & 0.018 & 4 & 0.11 \\
5 & 50 & 0.020 & 5 & 0.12 \\
\hline
\end{tabular}

Table-2:

\begin{tabular}{|l|l|l|l|l|}
\hline Sl.No & $\begin{array}{l}\text { Peak } \\
\text { position } \\
2 \theta\end{array}$ & $\begin{array}{l}\text { X-ray } \\
\text { Wavelength }\end{array}$ & $\begin{array}{l}\text { Reflection } \\
\text { order }\end{array}$ & XRD d Value \\
\hline 1 & 60 & 0.030 & 6 & 0.18 \\
2 & 70 & 0.040 & 7 & 0.24 \\
3 & 80 & 0.050 & 8 & 0.31 \\
4 & 90 & 0.060 & 9 & 0.38 \\
5 & 100 & 0.070 & 10 & 0.4 \\
\hline
\end{tabular}

Table-3:

\begin{tabular}{|l|l|l|l|l|}
\hline S1.No & $\begin{array}{l}\text { Peak position } \\
2 \theta\end{array}$ & $\begin{array}{l}\text { X-ray } \\
\text { Wavelength }\end{array}$ & Reflection order & XRD d Value \\
\hline 1 & 110 & 0.080 & 11 & 0.54 \\
2 & 120 & 0.090 & 12 & 0.62 \\
3 & 130 & 0.100 & 13 & 0.72 \\
4 & 140 & 0.101 & 14 & 0.75 \\
5 & 150 & 0.102 & 15 & 0.79 \\
\hline
\end{tabular}

Table-4:

\begin{tabular}{|l|l|l|l|l|}
\hline Sl.No & $\begin{array}{l}\text { Peak position } \\
2 \theta\end{array}$ & $\begin{array}{l}\text { X-ray } \\
\text { Wavelength }\end{array}$ & Reflection order & XRD d Value \\
\hline 1 & 160 & 0.103 & 16 & 0.84 \\
2 & 170 & 0.104 & 17 & 0.89 \\
3 & 180 & 0.105 & 18 & 0.94 \\
4 & 190 & 0.106 & 19 & 1.01 \\
5 & 200 & 0.107 & 20 & 1.09 \\
\hline
\end{tabular}

Table-5:

\begin{tabular}{|l|l|l|l|l|}
\hline S1.No & $\begin{array}{l}\text { Peak position } \\
2 \theta\end{array}$ & $\begin{array}{l}\text { X-ray } \\
\text { Wavelength }\end{array}$ & Reflection order & XRD d Value \\
\hline 1 & 300 & 0.108 & 21 & 2.27 \\
2 & 400 & 0.109 & 23 & 2.38 \\
3 & 500 & 0.110 & & 2.48 \\
\hline
\end{tabular}


International Advanced Research Journal in Science, Engineering and Technology

Impact Factor $7.105 \div$ Vol. 9, Issue 1, January 2022

DOI: 10.17148/IARJSET.2022.9142
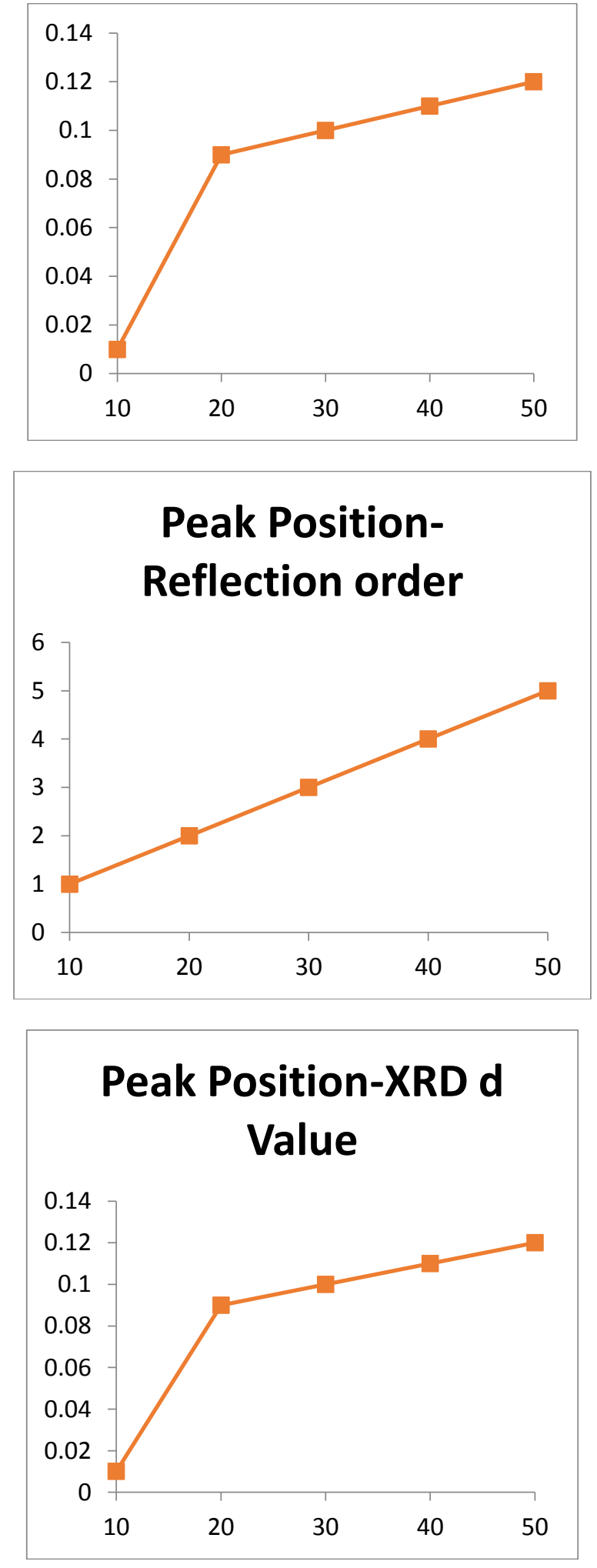

RESULTS AND DISCUSSION:

X-beam diffraction (XRD) strategies and procedures, as applied to material portrayal issues and tests, are inspected. Regular and synchrotron X-beam sources are talked about, and the utilization of XRD strategies to construction and stage assurance, just as anxiety, multi-facet organization and morphology, and semiconductor portrayal are presented.Bone is an extraordinary material having primary order at various length scales. To appropriately 


\section{International Advanced Research Journal in Science, Engineering and Technology \\ Impact Factor $7.105 \div$ Vol. 9, Issue 1, January 2022 \\ DOI: 10.17148/IARJSET.2022.9142}

comprehend the mechanical properties of bone at the tissue level, it is important to have data about the design, association and qualities of the fundamental underlying parts down to the nanoscale, just as the communication between various primary levels. In light of the primary intricacy in bone, data on mass properties generally mirrors the tissue strength, break or deformity; be that as it may, the basic beginnings are not known except if the lower-level constructions are explored.

Subsequently, it stays a significant test to uncover, non-disastrously and painlessly, how the perceptible bone attributes are impacted by the microstructural conduct. Such information would help understanding bone tissue and creating up and coming age of biomaterials, biomimetic plans and bio-enlivened nanocomposites for designing and clinical applications. It would likewise empower legitimate evaluation of matured and sick bones for osteoporosis (weak and permeable bone), osteopetrosis (profoundly thick bone), bone growths and different expires which influence the firmness, strength and durability of bone $[1,2]$

Conclusion: At the nanostructure level (size under $1 \mu \mathrm{m}$ ), bone can be considered as a multi-stage nanocomposite comprising of a natural stage (32-44\% bone volume), an inorganic stage (33-43\% bone volume) and water (15-25\% bone volume) [3]. The fundamental component of the natural stage is type I collagen that involves $90 \%$ of the absolute protein [8]. The inorganic stage comprises of nanosized apatite-like mineral precious stones, generally hydroxyapatite $\left(\mathrm{Ca}_{10}\left(\mathrm{PO}_{4}\right) 6(\mathrm{OH})_{2}\right)$ having a hexagonal grid design, and present as plates with a normal size of $50 \times 25 \times 3 \mathrm{~nm}$ [3]. These mineral precious stones are situated inside the hole cross-over area of staggered designed collagen strands and are found to develop with a particular glasslike direction. The crystallographic c-pivot of a mineral precious stone concurs with the hub of balance corresponding to the long element of the gem; it is typical to the (002) grid plane and has a solid favored direction corresponding to the long tomahawks of the collagen strands $[4,5]$. The mineral gems likewise develop outside the collagen filaments. Along with collagen filaments, these intra-and extra-fibrillar minerals establish a mineralized fibril structure. The hydroxyapatite crystallites are weak with low elasticity, while the protein-rich collagen filaments are intense and genuinely amazing in pressure; accordingly their blend invigorates bone both high strength and high toughness [6].

\section{REFERENCES:}

1. WagnerH DWeinerS 1992 J. Biomech. 251311 http://dx.doi.org/10.1016/0021-9290(92)90286A 00219290 [Crossref], [PubMed], [Web of Science ®], [Google Scholar]

2. CullityB DStockS R 2001 Biological Mineralization IZipkin New York Wiley p 227 [Google Scholar]

3. KlugH PAlexanderL E 1974 X-ray Diffraction Procedures — For Polycrystalline and Amorphous Materials New York Wiley [Google Scholar]

4. de JongW F 1926 Recueil des Travaux Chimiques des Pays-Bas 45445 http://dx.doi.org/10.1002/recl.v45:6 [Crossref], [Google Scholar]

5. FujisakiKTadanoSSasakiN $2006 \mathrm{~J}$. 39579 http://dx.doi.org/10.1016/j.jbiomech.2005.01.001 00219290 [Crossref], [PubMed], [Web of Science ®], [Google Scholar]

6. SasakiNShukunamiNMatsushimaNIzumiY 1999 J.Biomech. 32285 http://dx.doi.org/10.1016/S00219290(98)00174-2 00219290 [Crossref], [PubMed], [Web of Science ®], [Google Scholar]

$\begin{array}{llll}\text { 7. AlmerJ DStockS } & \text { R } 2007 \mathrm{~J} . & \text { Struct }\end{array}$ 157365 http://dx.doi.org/10.1016/j.jsb.2006.09.001 10478477 [Crossref], [PubMed], [Web of Science ®], [Google Scholar]

8. GuptaH SSetoJWagermaierWZaslanskyPBoeseckePFratz IP 2006 Proc. Natl Acad. Sci. 10317741 http://dx.doi.org/10.1073/pnas.0604237103 0027-8424 1091-6490 [Crossref], [PubMed], [Web Science ${ }^{\circledR}$ ], [Google Scholar] 